\title{
DESIGN OF COMPOSITE MATERIAL FOR COST EFFECTIVE LARGE SCALE PRODUCTION OF COMPONENTS FOR FLOATING OFFSHORE STRUCTURES
}

\author{
Blommaert Chris, Degrieck Joris, Van Paepegem Wim \\ Department of Mechanical Construction and Production \\ Ghent University (UGent), Gent, Belgium
}

\begin{abstract}
Today, the European Union (EU) is dependent on import for 50\% of its energy supply. By 2030 this could easily become $70 \%$. This makes the EU economically vulnerable. Hence, the EU made an effort to promote renewable energy. The SEEWEC project, an example of this, has been launched at the end of 2005 within the Sixth Framework of the EU. SEEWEC stands for Sustainable Economically Efficient Wave Energy Converter. One of the tasks of Ghent University, as a partner in the project, is the design of composite material for cost effective large scale production of floating point absorbers. For this, the first important steps are taken. A small filament winding machine has been designed to produce eggs on lab scale. For experimental tests on the strength of the egg and pressure distribution of the water, a set up for lab scale slamming tests was designed and built. The machine is designed for the testing of a variety of structures. Validation of the analytical formulas for slamming is to be achieved through these experiments. First, an assessment of the machine occurs by testing a rigid cone of 45 degrees for comparison with the Peseux model. Next, a rigid and a deformable cylinder will be tested and compared.
\end{abstract}

\section{INTRODUCTION}

The Kyoto agreement states that by 2012 an important decrease of greenhouse gasses (GHG), like $\mathrm{CO}_{2}$, has to be accomplished. The use of traditional fossil fuels can and will lead to the global warming with possible climate changes as a consequence. Also, the environmental pollution gains importance. The European Union (EU) is dependent on import for $50 \%$ of its energy supply. By 2030 this could easily become $70 \%$. This makes the EU economically vulnerable.

Hence, the EU made an effort to promote renewable energy. E.g. solar, biomass, wind and ocean energy can all give a small contribution. Wave energy is a small player on the energy market. However, it has a lot of potential. The European Atlantic coast wave climate is characterised by large energy. Waves can travel for thousands of kilometres with almost no loss of energy. Wave energy has some advantages: in comparison with solar energy, waves are more present, certainly at times when energy is needed the most (winter). In addition, waves have more energy per square meter than wind and solar energy.

However, to improve the transition from technology to real wave energy converters and to insure their value on the global energy market, extensive research is necessary on fundamental as well as on applied level. The most critical aspect of the development of a Wave Energy Converter (WEC) is the structural design. It needs to be very solid but at the same time the material and fabrication costs has to be limited. This clarifies why wave energy is at the moment not exploited on a global level. 


\section{SEEWEC}

Within the Sixth Framework of the EU, the SEEWEC project has been launched at the end of 2005. SEEWEC stands for Sustainable Economically Efficient Wave Energy Converter. The different partners participating in the project are: Ghent University (Belgium), Spiromatic NV (Belgium), ABB (Sweden), Standfast Yachts (Netherlands), Brevik Engineering A.S. (Norway), Marintek (SINTEF) (Norway), Norwegian University of Science and Technology (Norway), Instituto Superior Técnico (Portugal), Chalmers University of Technology (Sweden), Fred Olsen Ltd. (UK), Natural Power Consultants Ltd. (UK)

In the project a floating wave energy converter, the $\mathrm{FO}^{3}$, is studied. With the means of point absorbers the energy of the waves will be captured. This "floating", "offshore" platform has the advantage that it can be used in deeper water where there is more energy available. Acknowledgement for the general concept is given to Fred Olsen Ltd. A $1 / 3^{\text {rd }}$ scale model is shown in figure 1 . The general objective of the SEEWEC project is the development of a $2^{\text {nd }}$ generation wave energy converter. The project is divided in different work packages. The department of Mechanical Construction and Production of UGent is mainly concerned with the fourth one, namely 'The design of composite material for cost effective large scale production.'

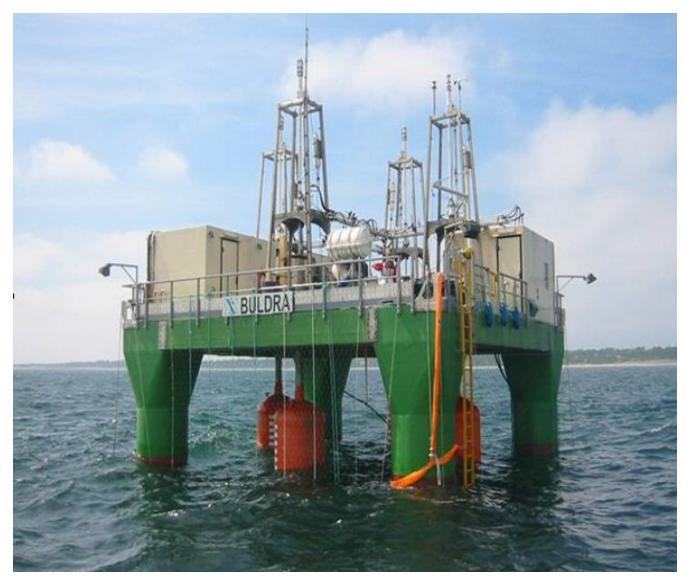

Figure 1: $1 / 3^{\text {rd }}$ scale model 'Buldra'

The first important steps are taken for the design and production of composite floating point absorbers (shortly called 'eggs'). The material used for this will be a fibre reinforced composite. One of the reasons why metal will not be used is corrosion and maintenance at sea.

The first task consists of choosing the basic fibre reinforced composite, and the determination of the basic mechanical characteristics. Next, the software package Cadwind has been used to calculate the winding path and material orientations. The thickness and orientation can be exported to Abaqus, where FEA has been done on the egg.

Next, a small filament winding machine has been designed to produce eggs on lab scale. For experimental tests on the strength of the egg and pressure distribution of the water, a set up for slamming tests was designed and built. This machine is designed to be used for different structures. Validation of the analytical formulas for slamming, and 
gaining more experimental data, is the purpose of these tests. A set of samples has been made: a cone, full cylinder, hollow cylinder and a possible shape for a scaled point absorber.

\section{PRODUCTION METHOD}

As mentioned, the material used for this will be a fibre reinforced composite due to reasons of maintenance at sea and corrosion. The eggs will probably be made of glass fibre and polyester resin due to reasons of costs in view of large scale production.

Filament winding is one of the chosen production processes of the egg. This production method is also suitable for large scale production at low cost, because the main cost is the mandrel. Additional, axisymmetric structures are easy to wind.

A software program, Cadwind, is used to calculate the winding pattern for any mandrel geometry. It determines whether a given shape can be wound. Some examples are shown in figure 2 .

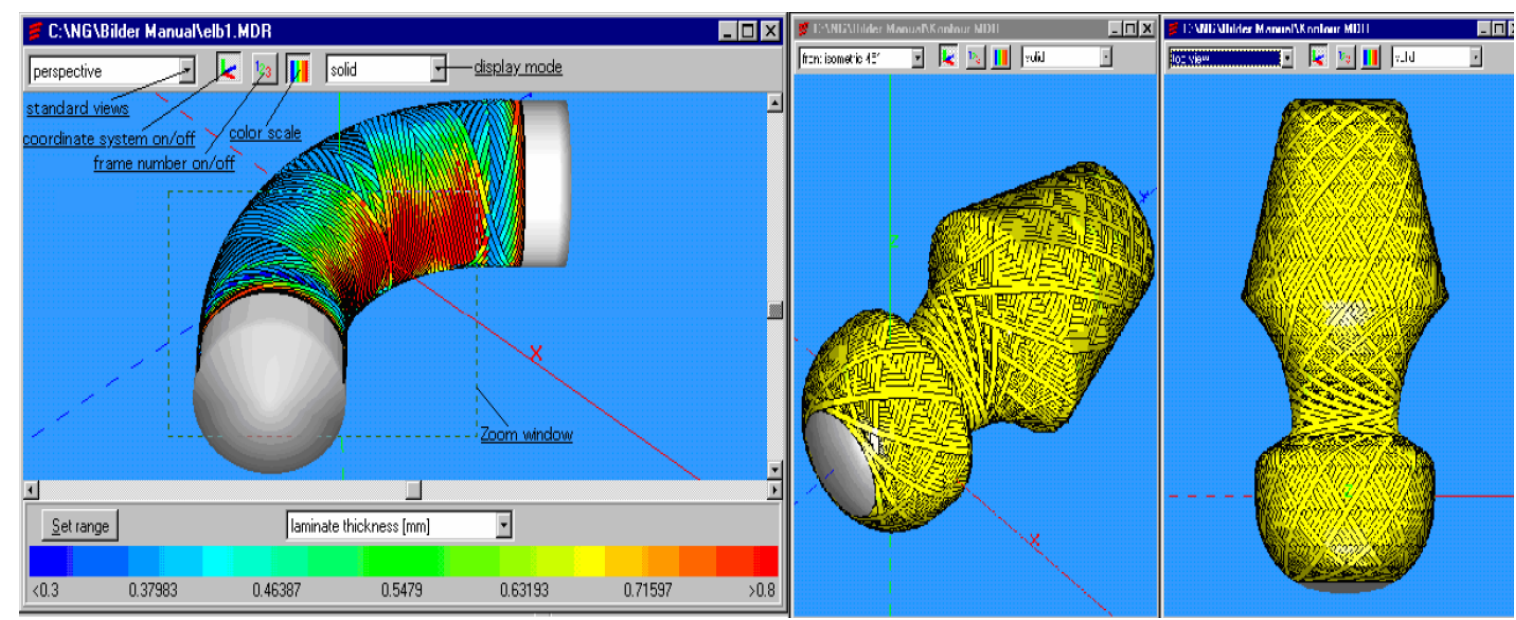

Figure 2: Examples of structures in Cadwind

Not all geometries can be manufactured in a winding process. It can occur that the fibres simply fall off the structure when there is not enough friction. This program is able to produce an export file with geometric (mesh) properties which can be used as import for Abaqus, a commercial finite element program, in which the strength and deformations can be calculated.

A small filament winding machine with a new controller and program to operate the machine easily has been designed to produce e.g. eggs on lab scale, as is shown in figure 3. Again, Cadwind proves to be a good tool. It generates all the coordinates for the axes of the winding machine so no geodetic path needs to be calculated manually. This file can be imported in the designed labview program on the winding machine.

A possible point absorber is made on lab scale for further tests. In figure 4 the result is shown. 


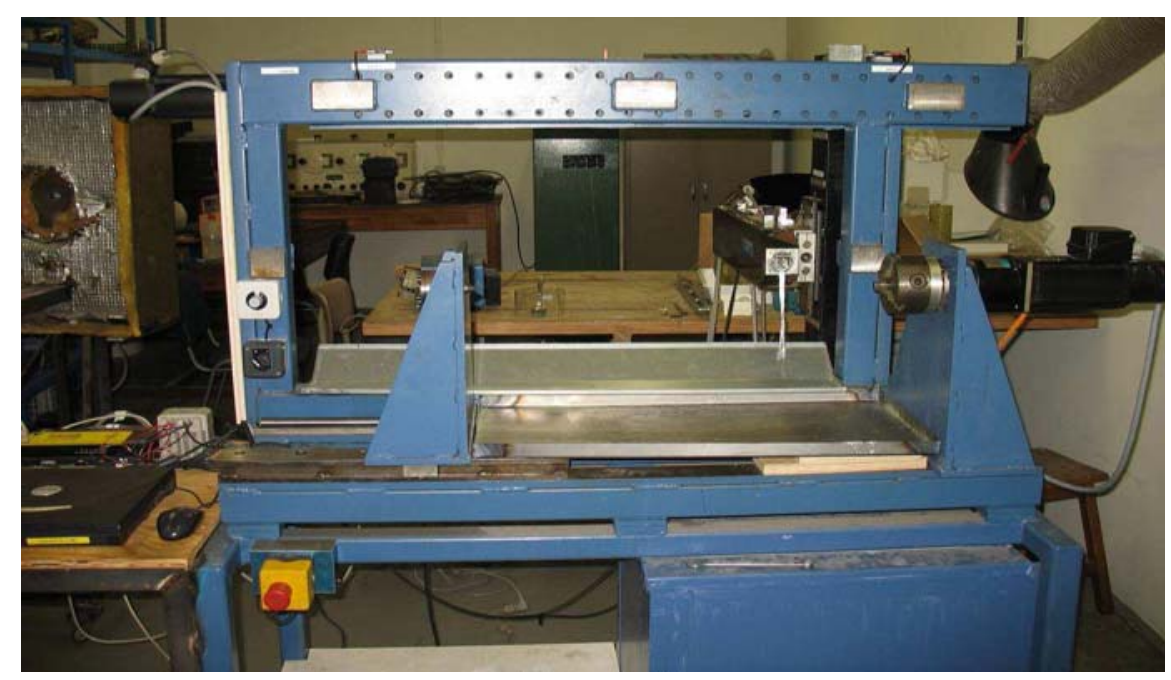

Figure 3: Small winding machine in the lab of UGent

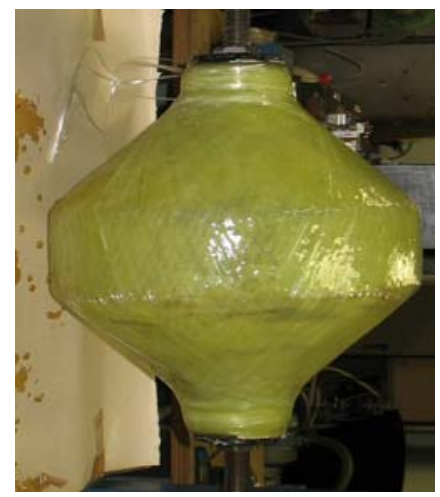

Figure 4: Possible scaled shape of point absorber; made on winding machine in the lab

\section{SLAMMING}

\subsection{Introduction 'slamming'}

Slamming is the periodical impact of waves on a floating or sailing structure. It is a complex process where the compressibility of water, the hydro-elasticity and aircushions/air bubbles can be relevant.

In the literature slamming is extensively studied for wedge shaped structures, like ships. In extreme cases slamming is the cause of fracture of a ship which can happen due to the pitch and heave of a ship. The probability of slamming of a ship is highest at the front where the maximum relative vertical velocity between the ship and the wave is situated. Another kind of slamming is breaking wave impact above the waterline.

Slamming is also an important factor for the strength of the composite eggs at sea. Here, the two kinds of slamming which are mentioned above are considered: the bottom slamming, namely the periodical falling of a structure on the water surface and second, the real breaking wave slamming (figure 5). 

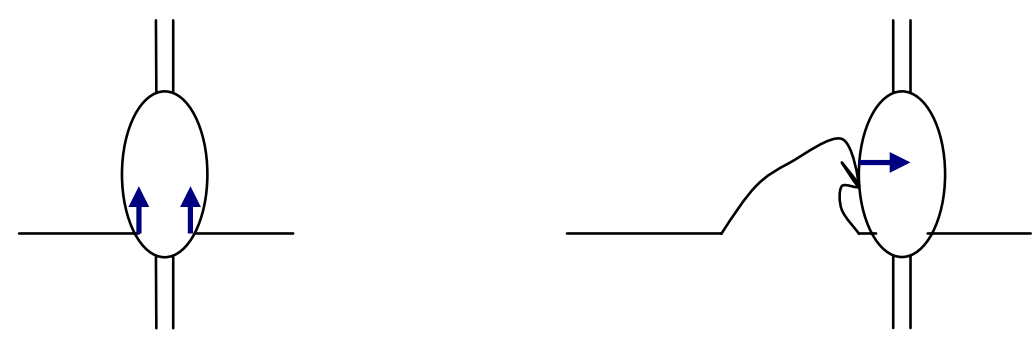

Figure 5: Egg bottom slamming (left) and egg breaking wave slamming (right)

A set up for slamming tests was designed and built for experimental tests. With those results, it should be possible to gain information about the strength of the egg, about the deformations and about the pressure distribution on the surface.

\subsection{Egg bottom slamming:}

The egg can come out of the water. At the moment it goes back in (hydrodynamic impact), it can be severely damaged due to high hydrodynamic pressures on its surface. Those impact pressures last only a fraction of a second but they are very local and can cause severe deformations of the material.

\subsection{Egg breaking wave slamming:}

Waves can not become infinitely steep. As soon as they reach the ratio height/length of $1 / 7$, they break. The most critical force on the egg occurs when they break at such a moment on the vertical surface of the egg.

\subsection{Set up - Laboratory}

The slamming set up is shown in figure 6. It is designed not only for the eggs, but also for experiments with other structures. A ladder is attached to a shaft. By means of a computer controlled motor the shaft is turned over. A water tank is placed under the ladder. Bottom slamming and breaking wave slamming, can both be tested in this set up.

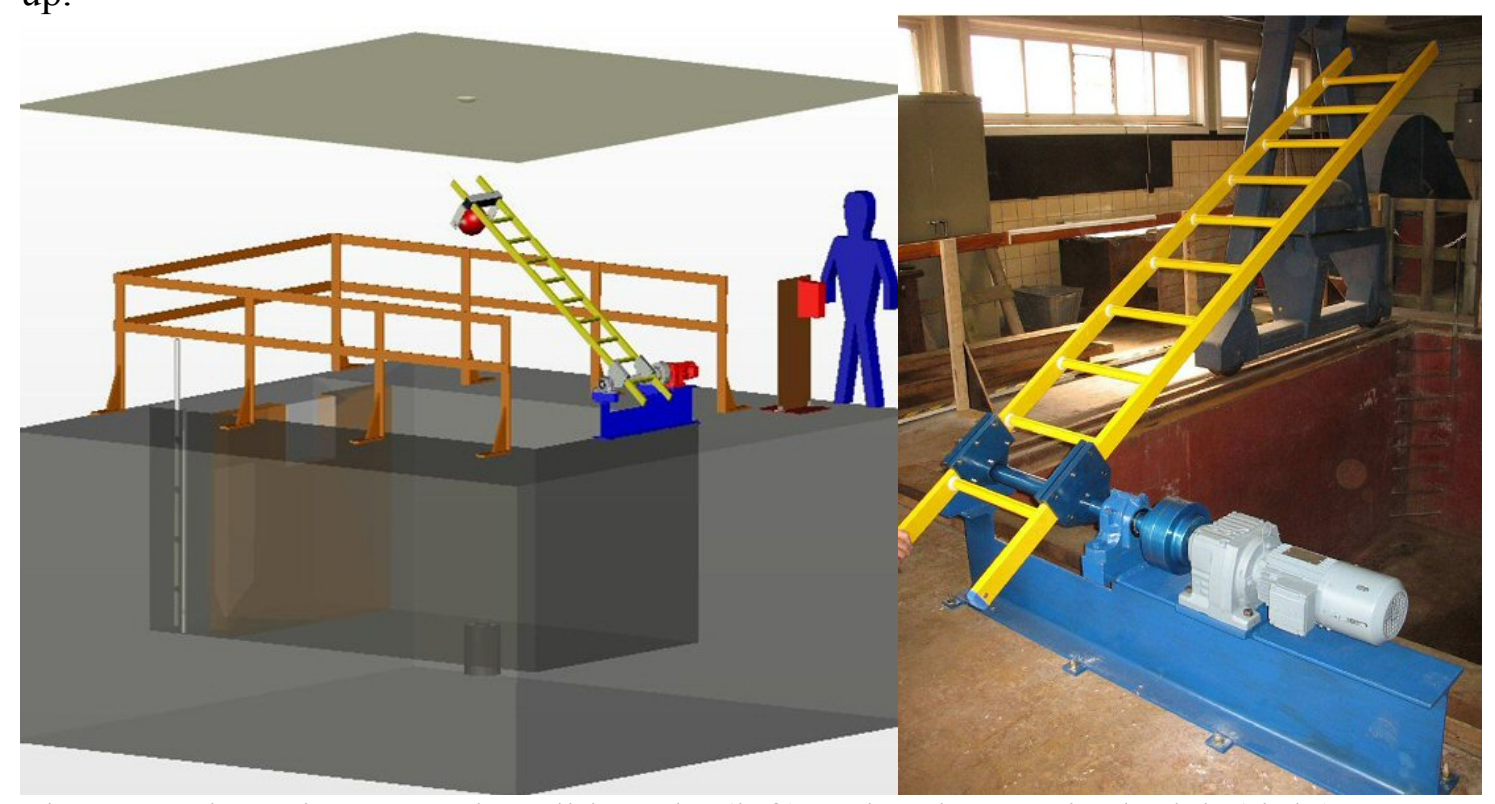

Figure 6: Slamming set up in solid works (left) and real set up in the lab (right) 
A high speed camera will be used during all the tests. For safety reasons (e.g. the water basin breaks down) a mirror will be used, so the camera can be mounted at a distance.

\section{TEST SAMPLES}

\subsection{Test case: Cone}

First, a cone will be tested. The cone is made out of polyurethane foam (PU). A topcoat is given to the cone to make it watertight. The cone is shown in figure 8.

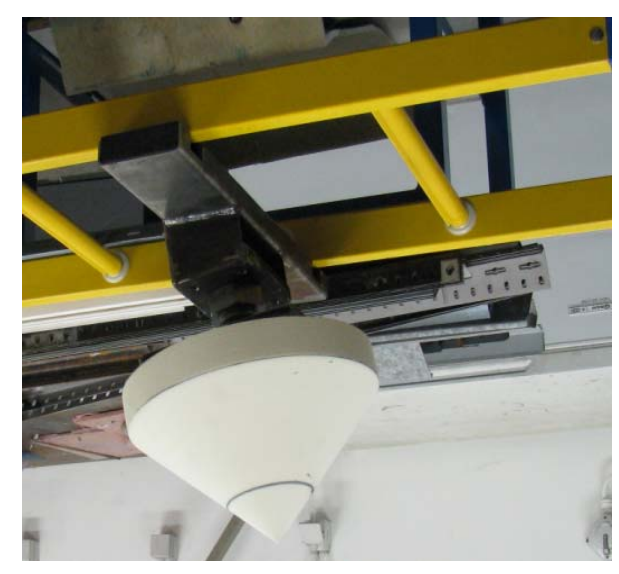

Figure 8: cone test sample attached to the ladder

The cone is instrumented with a pressure sensor, an accelerometer and two strain gages (perpendicular). This will be read out by labview.

This cone test case is chosen because straight forward information is available in the literature about this specific case. Wagner (1932) studied the impact of a 2D wedge with a small deadrise angle. The deadrise angle is the angle between the free water surface and the cone (see figure 9).

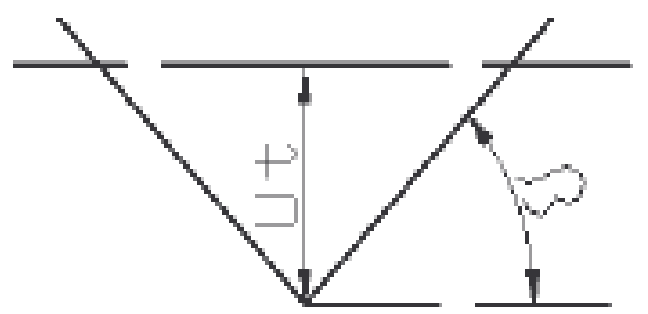

Figure 9: deadrise angle $\beta$

During time, corrections have been applied on the work on Wagner, e.g. for larger deadrise angles.

For three dimensional axisymmetrical bodies, the 3D flow can be described by a flow around a circular plate. Out of the known complex potential function of this flow, the pressure distribution in time for a conical shape can be retrieved. This has been done at the Department of Coastal Engineering of UGent [4] by S.Viktor. For a cone with a deadrise angle of 45 degrees the following formula can be used [4], [5]: 


$$
P 45=\frac{1}{2} \rho U^{2}\left[1-\frac{4\left(\frac{r}{U t}\right)^{2}}{\pi^{2}\left(\frac{16}{\pi^{2}}-\left(\frac{r}{U t}\right)^{2}\right)}+\frac{64}{\pi^{3} \sqrt{\frac{16}{\pi^{2}}-\left(\frac{r}{U t}\right)^{2}}}\right]
$$

This formula, reshaped for smaller deadrise angles, confirms previous numerical result of slamming tests done by Peseux [6].

The purpose of the cone test is to find a good correlation between the theory and this experiment. The results of this experiment can be used to assess our slamming machine. Thus, the cone test case is considered as a reference test.

\subsection{Test case: comparison full and hollow cylinder}

The next test consists out of two test samples, namely a full cylinder and a hollow one. Here, the aim of the tests is gaining experience on the effect of slamming on a rigid and deformable structure of a certain shape, e.g. a cylinder.

First, two cylinder mandrel plus connections (e.g. inner tube) have been made in PU. Next, the cylinder mandrel can be mounted on the winding machine. The two cylinders have been wound. Next, the production method is different for both cylinders. For the first one the mandrel stays inside, for the second one the foam is removed. Both cylinders are instrumented with again a pressure sensor, an accelerometer and two strain gages.

The measurements will occur in the middle of the cylinder to reduce side effects. A cylinder test sample is shown in figure 10 .

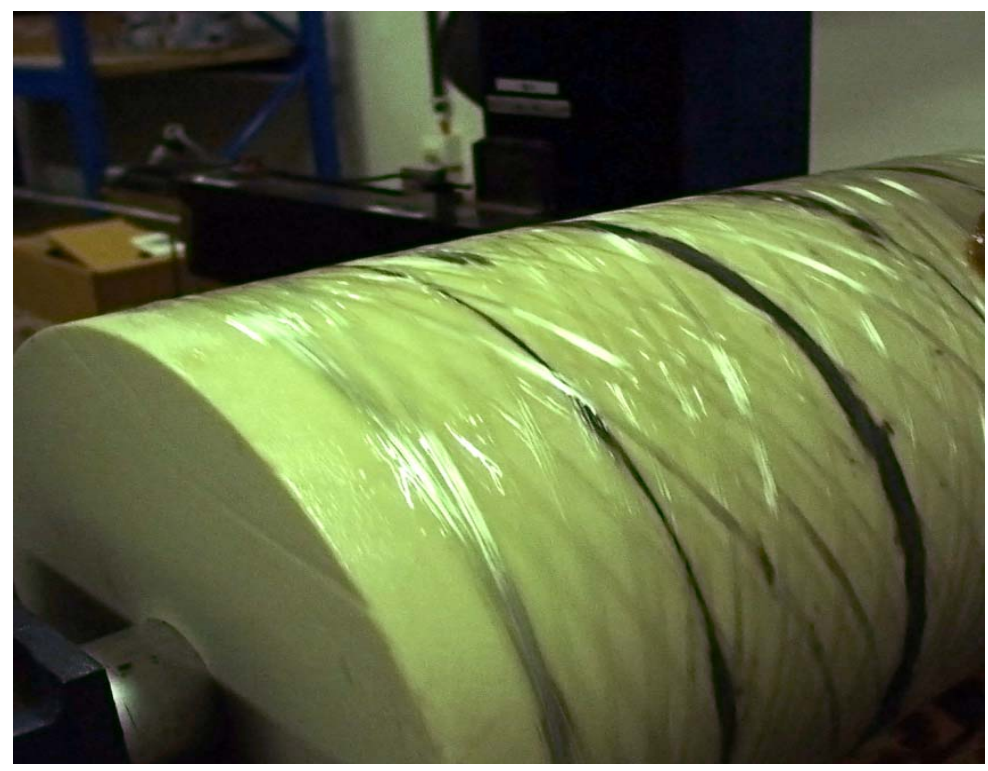

Figure 10: full cylinder test sample on the winding machine of the lab 


\subsection{Test case: a possible shape of point absorber}

Also, a lab scale test of a possible point absorber will occur (see figure 5). Breaking wave slamming is more critical for the eggs in comparison with bottom slamming. This is due to reasons of stiffness. Since breaking wave slamming is the most critical one, the egg will be tested on its side. Pressure, acceleration and strains will be measured again.

Breaking wave tests can also be done in the wave gutter in Flanders Hydraulics Research Laboratory in Borgerhout, Belgium. There, the possibility to generate waves of certain height is available. In the previous set up however, a falling speed is given. A twin structure will be tested in the wave gutter in Borgerhout. There, a given significant wave height (corresponding with certain celerity) will result in a certain pressure. If the velocity of the falling speed in the previous set up and this celerity is about the same, the measured pressures should also be in the same range. The comparison of both experiments is an assessment of the usability of this slamming set up for the breaking wave slamming.

\section{CONCLUSIONS AND FUTURE WORK}

The first important steps are taken for the design and production of composite floating point absorbers. The material used for this will be a fibre reinforced composite. One of the reasons why metal will not be used is corrosion and maintenance at sea. One of the possible production methods is filament winding; chosen due to axisymmetric structures and also due to the emphasis on large production series. The software package Cadwind has been used to calculate the winding path and material orientations and Abaqus has been used for FEA calculations on the egg. A small filament winding machine has been designed to produce test samples on lab scale. Also, a set up for slamming tests was designed and built. A set of test samples has been made: a cone, full cylinder, hollow cylinder and a possible shape for a scaled point absorber. The results of the cone test should give a good correlation with the theory. Then, this test can be considered as a reference test. Further slamming tests need to be done.

\section{ACKNOWLEDGEMENTS}

This research is performed within the framework of the SEEWEC project of the European Commission. Credits for the general concept are given to Fred. Olsen.

\section{REFERENCES}

1- M.T. Pontes, G.A. Athanassoulis et al., The European Wave Energy Resource, 3rd EWEC, Patras,

2- http://library.abb.com/GLOBAL/SCOT/scot271.nsf/VerityDisplay/1E2FADD298A58 D14C12571D900412482/\$File/29-31\%203M646 ENG72dpi.pdf

3- Abdalla, F.H., Mutasher, S.A.(2005), Design and fabrication of a low cost filament winding machine, Universiti Putra Malaysia

4- S.Victor, Onderzoek naar slammingsverschijnselen bij point absorbers: experimenteel en literatuurstudie

5- M. Vantorre, Manoeuvreer- en Zeegangsgedrag van Maritieme Constructies, cursus 2nd Master of Mechanical Engineering, Universiteit Gent, academiejaar 2005 - 2006, hoofdstuk 4, p. $15-24$ 
6- B. Peseux, L. Gornet, B. Donguy, Hydrodynamic impact: Numerical and experimental investigations, 2005, Journal of Fluids and Structures 21, 277 303. 